\title{
Hydraulic Fracturing Stress Measurements and Their Implication for the Design of the First Concrete Lined Pressure Shaft in Sri Lanka
}

\author{
Hadi Barghamadi ${ }^{1}$, P. Nater ${ }^{1}$ and P. Huwyler ${ }^{2}$ \\ 1. Mahab Ghodss Consulting Engineering Co., Tehran, Iran \\ 2. Pöyry Switzerland Ltd., 1618037 Zurich, Switzerland
}

\begin{abstract}
The Uma Oya Multipurpose Development Project (UMDP) is a water transfer, hydropower and irrigation in the south-eastern part of the central highland region of Sri Lanka. During geotechnical site investigation program 42 hydraulic fracture tests and 42 impression packer tests were carried out in 3 boreholes to about $840 \mathrm{~m}$ depth. Based on the stress measurements the minimum and maximum horizontal stress ratios were calculated. In situ stress computations at all the tests were based on the assumption that the principal stress components were vertical $\left(\sigma_{\mathrm{v}}\right)$ and horizontal $\left(\sigma_{\mathrm{H}}\right.$ and $\sigma_{\mathrm{h}}$, the maximum and minimum, respectively). The results of the measurements had a direct impact on the design of the major openings bearing a high overburden- the underground powerhouse and the transformer cavern — and revealed a significant optimization potential concerning the selection of the lining system of the pressure shaft.
\end{abstract}

Key words: Hydraulic fracturing, stress measurement, in situ stress, vertical stress, horizontal stress, pressure shaft.

\section{Introduction}

The UMDP (Uma Oya Multipurpose Development Project) incorporates both water transfer for irrigation and hydropower activities in the south-eastern part of the central highland region of Sri Lanka (for the location see Fig. 1 below). The design discharge is 19.5 $\mathrm{m}^{3} / \mathrm{s}$ and the installed capacity of the two Pelton turbines is $120 \mathrm{MW}$ in total. The project consists of two dams (Dyraaba \& Puhulpola), a link tunnel between the reservoirs (length $3.9 \mathrm{~km}$ ), a headrace tunnel (length $15.3 \mathrm{~km}$ ), a surge facility, the pressure shaft, an underground powerhouse and a transformer cavern and a tailrace tunnel (length $3.7 \mathrm{~km}$ ).

The central structures of the scheme are the underground powerhouse and the transformer cavern bearing an overburden of approx. $700 \mathrm{~m}$ each (turbine axis $230 \mathrm{~m}$ a.s.l.). From a design perspective, the focus is on the pressure shaft with an excavation diameter of

Corresponding author: H. Barghamadi, M.Sc., project manager, research field: rock mechanics.
$3.2 \mathrm{~m}$, an inner diameter of $2.5 \mathrm{~m}$ and a total vertical length of approx. $630 \mathrm{~m}$ from the upper bend $(860.0$ a.s.l.) within the valve chamber to the lower bend (230.5 $\mathrm{m}$ a.s.1.). The pressure shaft will be excavated by raise drill technique creating a smooth excavation surface and causing minimum disturbance to the surrounding rock mass.

A firm understanding of the in-situ stress conditions including the orientation of the principal stresses is crucial for the design of the abovementioned structures. As for the caverns it is favourable to align their axis with the maximum principal stress direction. Designing the concrete lined pressure shaft the acting minimum in-situ stresses have to overcome the design water pressure to ensure for relative tightness and for the integrity of the rock mass.

Additionally, the in-situ stress measurements performed in the vicinity of the pressure shaft location (tests in the boreholes ST-1 and PH-1) can be considered as small scale experiments directly addressing the design situation of hydraulic jacking of 
the rock mass due to the internal water pressure.

The following Figure shows the geological section through the area of interest-pressure shaft-together with the locations of the boreholes ST-1, PH-1 and $\mathrm{PH}-2$, indicating the dominant bedrock units.

\section{In-situ Stress Measurement}

\subsection{Testing Procedure}

HF (hydraulic fracturing) and HTPF (hydraulic testing of pre-existing fractures) are well-established methods for measuring the minor principal stress and the direction of the major principal stress. During the feasibility studies for the UMDP in total 42 hydraulic fracture tests and 42 impression packer tests were carried out in three boreholes (DT-5A, ST-1 and PH-1, see also Tables 1-3). The measurements were performed using a wireline system, where a straddle packer tool is directed to a test interval within an existing borehole via a logging cable driven by an electric winch. The test interval is then separated by the packers and the fluid pressure in the interval is varied

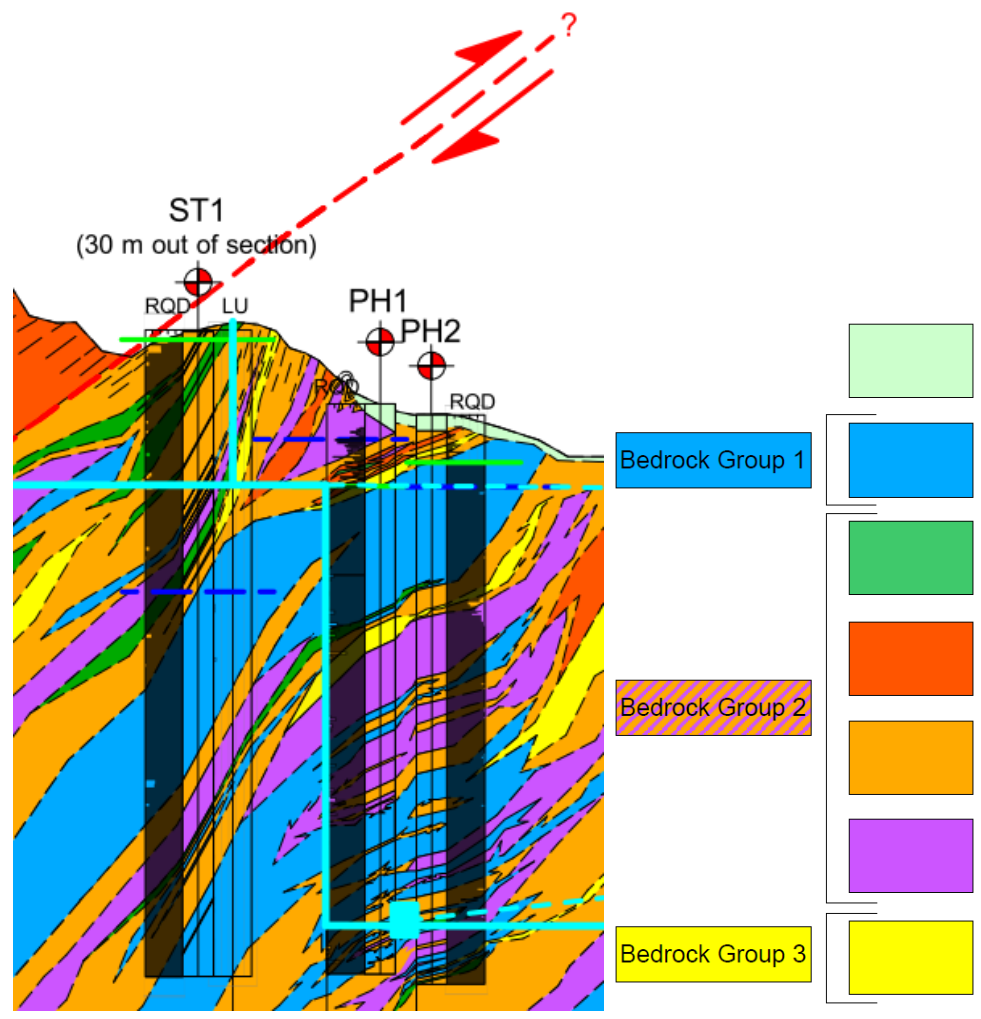

Colluvial Debosits, undifferentiated

(indicating sections with almost no bedrock outcrops)

Marbles and Calc-Silicate Gneisses, massive

Biotite-Hornblende Gneiss / -Fels

Garnet Gneisses, up to $70 \%$ Garnets and up to $3 \mathrm{~cm}$ Diameter

Leucocratic Garnet-Quartz-Feldspar Gneisses, banded to massive

Charnockitic Gneisses, undifferentiated, dark gray

Quartz-rich Gneisses to pure Quartzites, banded

Fig. 2 Geological section in the pressure shaft area [1]. 
Table 1 Summary of the tests results and stress calculations, Borehole PH-1.

\begin{tabular}{lllllllllll}
\hline Depth $(\mathrm{m})$ & Elevation $(\mathrm{m})$ & $P_{\mathrm{c}}(\mathrm{MPa})$ & $P_{\mathrm{r}}(\mathrm{MPa})$ & $P_{\mathrm{co}}(\mathrm{MPa})$ & $P_{\mathrm{si}}(\mathrm{MPa})$ & $\begin{array}{l}\text { Frac strike } \\
(\mathrm{deg})\end{array}$ & $\begin{array}{l}\text { Frac dip } \\
(\mathrm{deg})\end{array}$ & $\sigma_{\mathrm{v}}(\mathrm{MPa})$ & $\sigma_{\mathrm{h}}(\mathrm{MPa})$ & $\sigma_{\mathrm{H}}(\mathrm{MPa})$ \\
\hline 731 & 181.0 & 20.35 & 13.84 & 6.51 & 11.4 & 68 & 79 & 20.5 & 11.4 & 20.4 \\
712 & 200.0 & 12.57 & & & & 80 & 82 & 19.9 & \\
695 & 217.0 & 15.8 & 10 & 5.8 & 10.9 & 25 & 74 & 19.5 & 10.9 & 22.7 \\
680 & 232.0 & 15.46 & 9.54 & 5.92 & 9.14 & 152 & 90 & 19.0 & 9.1 & 17.9 \\
658 & 254.0 & 22.25 & 14.9 & 7.35 & 15.7 & 25 & 86 & 18.4 & 15.7 & 32.2 \\
640 & 272.0 & 22.05 & 15 & 7.05 & 11.37 & 12 & 73 & 17.9 & & \\
620 & 292.0 & 21.1 & 14.5 & 6.6 & 16.7 & 75 & 80 & 17.4 & 16.7 & 35.6 \\
601 & 311.0 & 16.9 & 12.7 & 4.2 & 11.5 & 15 & 68 & 16.8 & \\
570 & 342.0 & 13.1 & 7.2 & 5.9 & 6.6 & 160 & 90 & 16.0 & 6.6 & 12.6 \\
\hline
\end{tabular}

Table 2 Summary of the tests results and stress calculations, Borehole ST-1.

\begin{tabular}{|c|c|c|c|c|c|c|c|c|c|c|}
\hline Depth (m) & Elevation (m) & $P_{\mathrm{c}}(\mathrm{MPa})$ & $P_{\mathrm{r}}(\mathrm{MPa})$ & $P_{\text {co }}(\mathrm{MPa})$ & $P_{\mathrm{si}}(\mathrm{MPa})$ & $\begin{array}{l}\text { Frac strike } \\
(\mathrm{deg})\end{array}$ & $\begin{array}{l}\text { Frac dip } \\
\text { (deg) }\end{array}$ & $\sigma_{\mathrm{v}}(\mathrm{MPa})$ & $\sigma_{\mathrm{h}}(\mathrm{MPa})$ & $\sigma_{\mathrm{H}}(\mathrm{MPa})$ \\
\hline 199 & 847.8 & 6.9 & 5.32 & 1.38 & 4.96 & 38 & 75 & 5.6 & 5.0 & 9.6 \\
\hline 218 & 828.8 & 13.8 & 10 & 3.8 & 7.45 & 46 & 27 & 6.1 & & \\
\hline 269 & 777.8 & 11.8 & 7.4 & 4.4 & 6.8 & 161 & 77 & 7.5 & 6.8 & 13.0 \\
\hline 290 & 756.8 & 7.75 & 5.6 & 2.15 & 5.56 & 81 & 84 & 8.1 & 5.6 & 11.1 \\
\hline 376 & 670.8 & & 10.4 & & 8.2 & 54 & 77 & 10.5 & 8.2 & 14.2 \\
\hline 412.2 & 634.6 & 13.25 & 11 & 2.25 & 11 & 73 & 85 & 11.5 & 11.0 & 22.0 \\
\hline 452 & 594.8 & 19.2 & 12 & 7.2 & 9.9 & 25 & 90 & 12.7 & 9.9 & 17.7 \\
\hline 481 & 565.8 & 18.9 & 9.3 & 9.6 & 5.3 & 50 & 70 & 13.5 & & \\
\hline 510 & 536.8 & 12.94 & 7.6 & 5.34 & 6.5 & 16 & 76 & 14.3 & 6.5 & 11.9 \\
\hline 549 & 497.8 & 19.6 & 12 & 7.6 & 11.5 & 20 & 90 & 15.4 & 11.5 & 22.5 \\
\hline 619 & 427.8 & 11.3 & 7.5 & 3.8 & 6.6 & 54 & 85 & 17.3 & 6.6 & 12.3 \\
\hline 657 & 389.8 & 12.76 & 9.6 & 3.16 & 9.05 & 83 & 75 & 18.4 & 9.1 & 17.6 \\
\hline 674 & 372.8 & 12.4 & 10.2 & 2.2 & 9.6 & 75 & 75 & 18.9 & 9.6 & 18.6 \\
\hline 687.9 & 358.9 & 14.2 & 11.8 & 2.4 & 11.87 & & & 19.3 & 11.9 & 23.8 \\
\hline 698 & 348.8 & 12.3 & 10 & 2.3 & 9.86 & 66 & 90 & 19.5 & 9.9 & 19.6 \\
\hline 710 & 336.8 & 17.9 & 14 & 3.9 & 16 & 118 & 90 & 19.9 & 16.0 & 34.0 \\
\hline 730 & 316.8 & 11.8 & & & & & & 20.4 & & \\
\hline 768.5 & 278.3 & & 13 & & 13 & 77 & 75 & 21.5 & 13.0 & 26.0 \\
\hline 790.05 & 256.7 & & 10.5 & & 10.4 & 78 & 75 & 22.1 & 10.4 & 20.7 \\
\hline 804 & 242.8 & & 11.4 & & 9.5 & 38 & 72 & 22.5 & & \\
\hline 826.68 & 220.1 & & 18.26 & & 13 & 71.5 & 82 & 23.1 & 13.0 & 20.7 \\
\hline 841 & 205.8 & & & & & & & 23.5 & & \\
\hline
\end{tabular}

Table 3 Summary of the tests results and stress calculations, Borehole DT-5A.

\begin{tabular}{|c|c|c|c|c|c|c|c|c|c|c|}
\hline Depth (m) & Elevation (m) & $P_{\mathrm{c}}(\mathrm{MPa})$ & $P_{\mathrm{r}}(\mathrm{MPa})$ & $P_{\text {co }}(\mathrm{MPa})$ & $P_{\mathrm{si}}(\mathrm{MPa})$ & $\begin{array}{l}\text { Frac strike } \\
\text { (deg) }\end{array}$ & $\begin{array}{l}\text { Frac dip } \\
\text { (deg) }\end{array}$ & $\sigma_{\mathrm{v}}(\mathrm{MPa})$ & $\sigma_{\mathrm{h}}(\mathrm{MPa})$ & $\sigma_{\mathrm{H}}(\mathrm{MPa})$ \\
\hline 243.5 & 847.5 & 7.3 & 5.2 & 2.1 & 4.6 & 31 & 90 & 6.8 & 4.6 & 8.6 \\
\hline 234.8 & 856.2 & & & & & 45 & 82 & 6.6 & & \\
\hline 226.5 & 864.5 & 9.073 & 4.8 & 4.273 & 5.9 & 39 & 82 & 6.3 & 5.9 & 12.9 \\
\hline 208.75 & 882.3 & 15.89 & 13.5 & 2.39 & 8 & 29.5 & 35 & 5.8 & & \\
\hline 193.2 & 897.8 & & 3.99 & & 3.5 & 40 & 74 & 5.4 & 3.5 & 6.5 \\
\hline 188 & 903.0 & 7 & 4.3 & 2.7 & 4.34 & 33 & 87 & 5.3 & 4.3 & 8.7 \\
\hline 180.1 & 910.9 & 6.86 & 4.8 & 2.06 & 5 & 20 & 82 & 5.0 & 5.0 & 10.2 \\
\hline 174.4 & 916.6 & & 4.9 & & 6.2 & 3 & 78 & 4.9 & 6.2 & 13.7 \\
\hline 169.1 & 921.9 & 7.54 & 5 & 2.54 & 4.85 & 69 & 87 & 4.7 & 4.9 & 9.6 \\
\hline 161.7 & 929.3 & 7.15 & 4.4 & 2.75 & 4.8 & 36 & 90 & 4.5 & 4.8 & 10.0 \\
\hline 153.9 & 937.1 & 6.4 & 3.8 & 2.6 & 3.65 & 38 & 86 & 4.3 & 3.7 & 7.2 \\
\hline
\end{tabular}



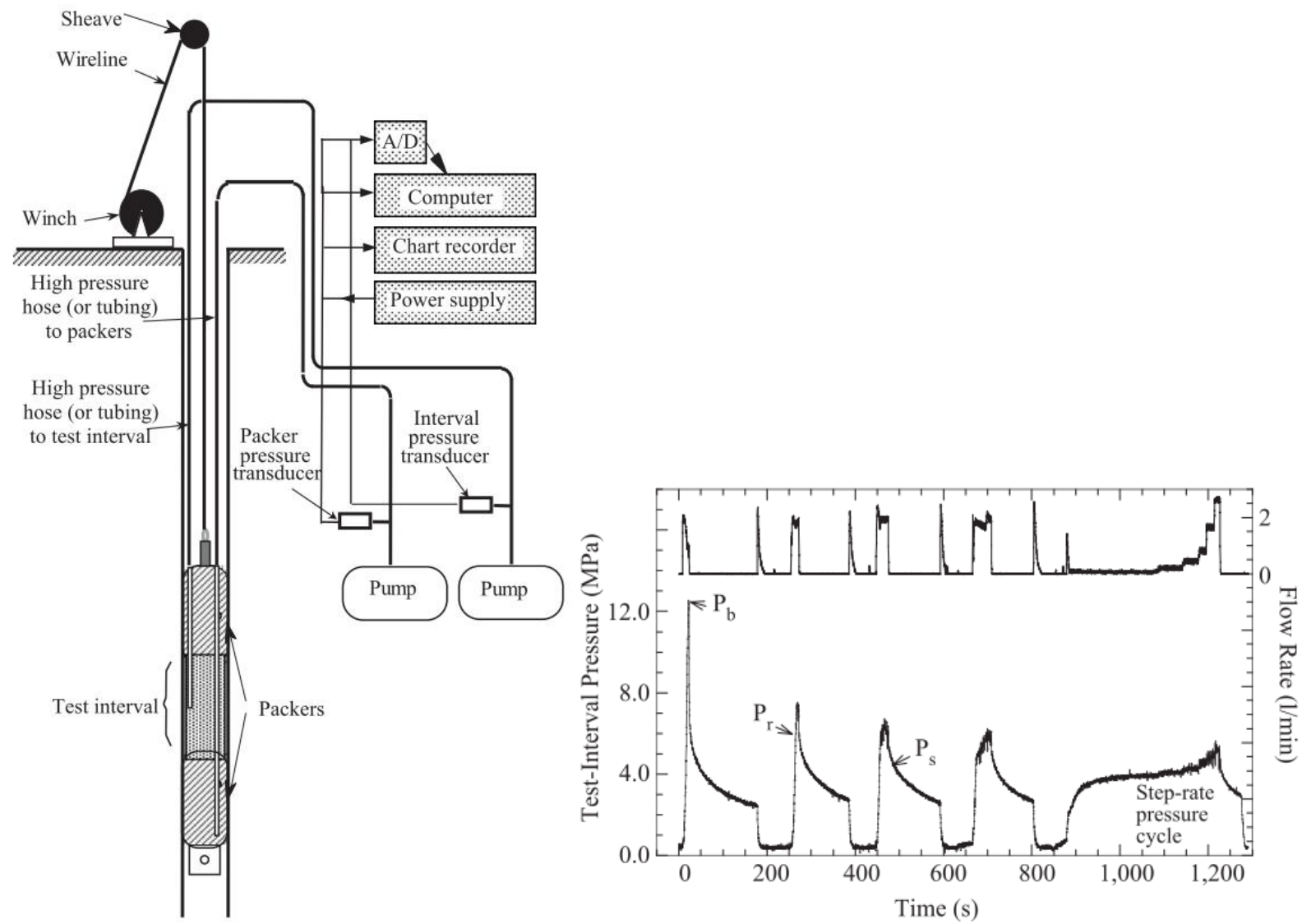

Fig. 3 (Left) Schematic view of a wireline system for HF/HTPF testing; (Right) Typical test-interval with pressure and flow rate versus time [2].

impression packer was placed within the test interval to capture the orientation and the inclination of the opened fracture as an indicator of the direction of the maximum horizontal stress $\sigma_{\mathrm{H}}$.

A schematic view of the test equipment with all its main components and a primary plot of the results is presented in Fig. 3.

\subsection{Interpretation of the Stress Measurements}

All in-situ stress computations are based on the assumption that the principal stress components are vertical $\left(s_{\mathrm{v}}\right)$ and horizontal $\left(s_{\mathrm{H}}\right.$ maximum and $s_{\mathrm{h}}$ minimum). The induced fractures of 32 out of the 42 tests could be characterized as vertical to sub-vertical where "sub-vertical" refers to a fracture inclination within $\pm 15^{\circ}$ from the vertical. The vertical stress $s_{\mathrm{v}}$ can be estimated considering the weight of overburden at the depth of the tests from the equation:

$$
\sigma_{v}=\gamma \times D
$$

Where:

$\gamma:$ is average unit weight of the overburden (taken as $\left.0.028 \mathrm{MN} / \mathrm{m}^{3}\right)$;

$D$ : Depth of the test interval [m].

The method of deriving the minimum horizontal stress $s_{\mathrm{h}}$ is quite reliable as the values are directly measured and no further interpretation is needed. Where the induced fractures are vertical or sub-vertical, the minimum horizontal stress $s_{\mathrm{h}}$ is defined to be equal to the shut-in pressure $P_{\mathrm{si}}$; the pressure needed to keep the fracture open or to guarantee for a constant flow. The theoretical and experimentally verified assumption is that the plane of the vertical or sub-vertical fracture is normal to the direction of the least horizontal stress (see Ref. [3]).

$$
\sigma_{h}=P_{s i}
$$

Where:

$P_{s i}$ : Shut-in pressure [MPa].

The calculation of the maximum horizontal stress $s_{\mathrm{H}}$ 
is based on the Kirsch solution [4] for deriving the stress distribution around a circular hole in an elastic medium subjected to far-field compressive stresses. The adapted equation is:

$$
\sigma_{H}=p_{c o}+3 \sigma_{h}-P_{c}-P_{p}
$$

where:

$P_{c}$ : Breakdown or critical pressure $[\mathrm{MPa}]$;

$p_{p}$ : Pore fluid pressure [MPa];

$p_{c o}:$ In-situ hydraulic tensile strength of the rock [MPa].

Solving Eq. (3) requires that the hydraulic tensile strength of the rock $P_{\text {co }}$ is known. As the tensile strength derived from Brazilian tests is not compatible with the required hydraulic tensile strength $P_{\text {co }}$, the value remains unknown. In case reliable laboratory testing is not feasible an alternative relation can be used, invoking the fracture reopening pressure $P_{\mathrm{r}}$. This pressure is assumed to be that at which the induced fracture, which has closed again completely after the initial pressure cycle, reopens. This time, however, the fracture reopening pressure does not need to overcome the tensile strength. Hence Eq. (3) simplifies to:

$$
\sigma_{H}=3 \sigma_{h}-P_{r}-p_{p}
$$

where:
$P_{r}$ : Reopening pressure [MPa].

Additionally, the reopening pressure $P_{\mathrm{r}}$ represents the resistance in the risk situation of hydraulic jacking of the rock mass while applying an internal water pressure (see also section 2.2).

Based on Ref. [5] recommendation for non-porous crystalline rocks, e.g. the Gneiss in the project area, the pore pressure can be considered to be negligible; $p_{\mathrm{p}}=0$ (see Ref. [6]). The stress evaluation corresponding to the abovementioned procedure is summarized in Tables 1-3.

Based on the stress measurements the minimum and maximum horizontal stress ratios were calculated and presented in Fig. 4 graphically.

\section{Shaft Lining Design}

\subsection{Design Criteria for the Shaft Lining}

The primary goal of the shaft lining is to guarantee for stability of the pressure system as it is a central and crucial part of the whole scheme and any repair and/or maintenance work causes downtimes both in water supply and energy production. For economic reasons the amount of water loss in the pressurized system is to be minimized - hence the placement of a steel lining is

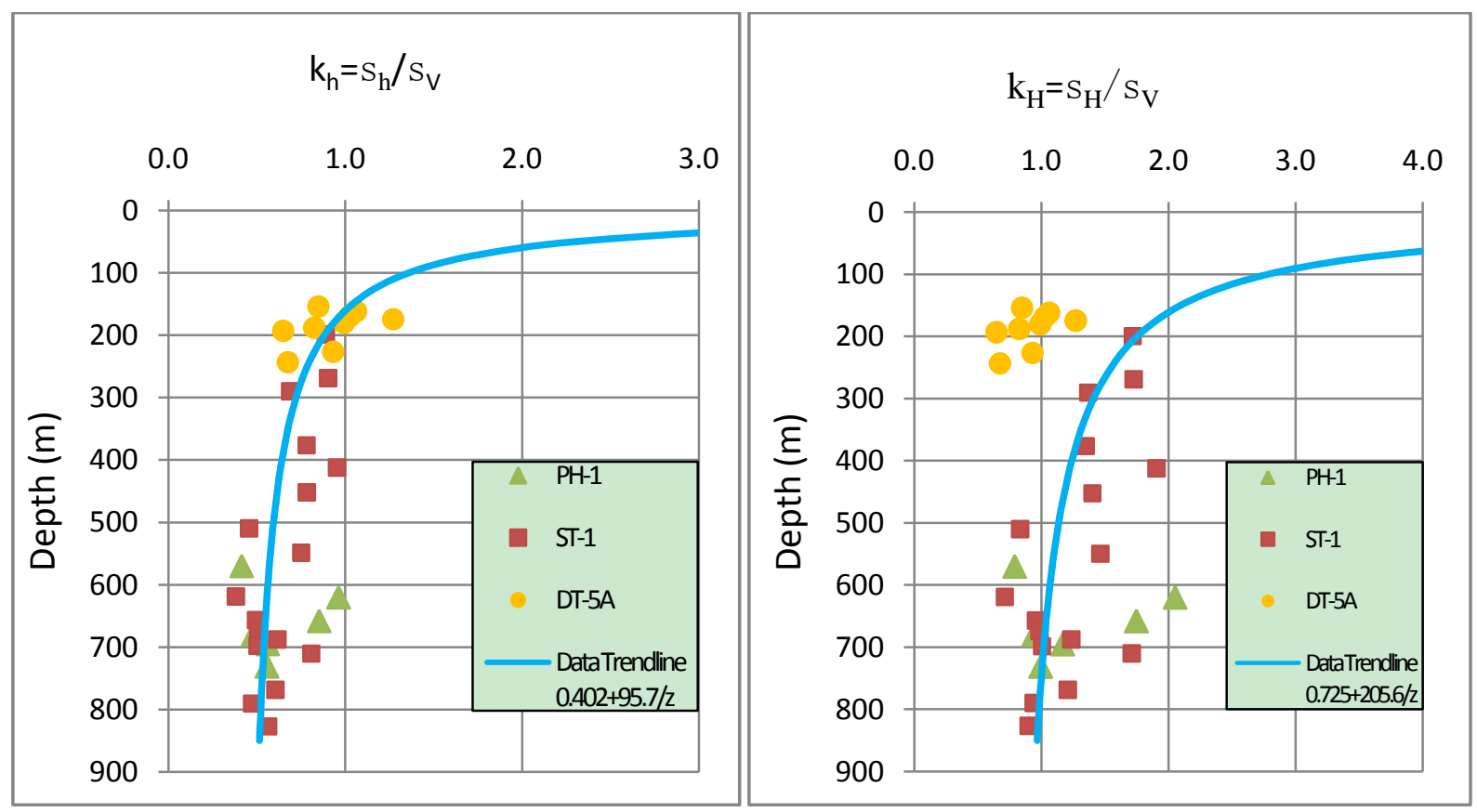

Fig. 4 (Left) Minimum horizontal stress ratio $K_{h}=\sigma_{h} / \sigma_{v}$; (Right) Maximum horizontal stress ratio $K_{H}=\sigma_{H} / \sigma_{v}$. 


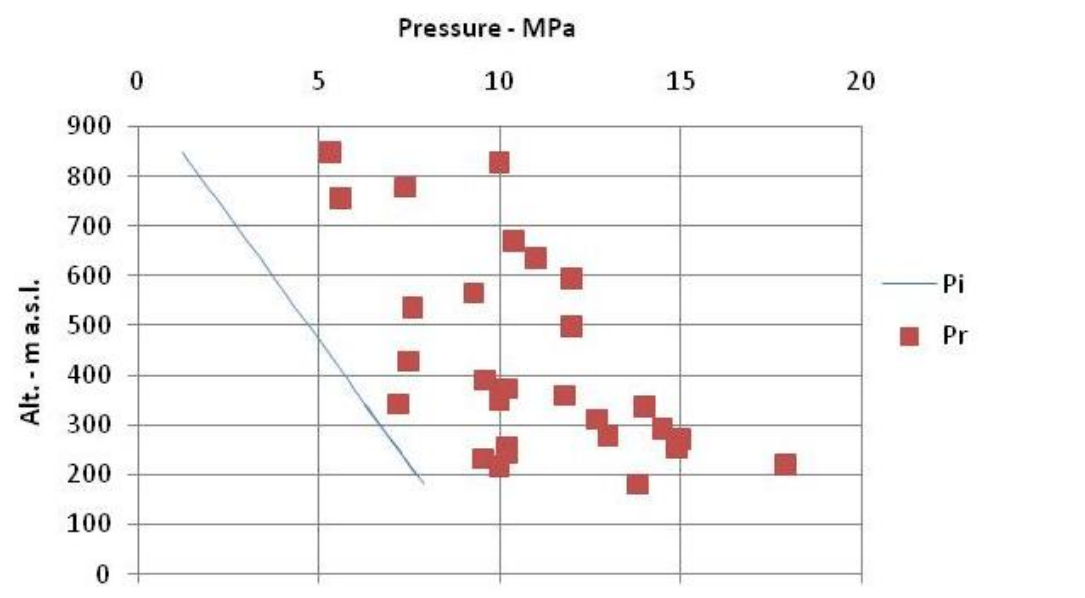

Fig. 5 Fracture reopening pressure $P_{\mathrm{r}}$ together with the design water pressure $P_{\mathrm{i}}$ for boreholes ST-1 and PH-1 [7].

the most common solution as it is completely water tight and self-bearing. The main disadvantages of steel liners are the high prime costs of steel and severe quality issues due to the need of high quality welding under the constrained conditions in the shaft and due to the need of long-term corrosion protection. Anticipating generally good rock mass conditions comprising firm bedrock units with low permeability and only few fractured zones, yielded optimization potential to be revealed by replacing the steel liner with a form concrete liner. The prime costs of concrete are low and maintenance has proven to be significantly less in similar configurations. Nevertheless, a reinforced concrete lining is required even in areas with excellent rock conditions to mitigate seepage flow together with washing out of material invoking cavities behind the lining and preventing local concrete break-outs or local spalling due to overstress, construction defects or concrete degradation.

\subsection{Major Hydraulic Design Scenarios}

The following information is taken from Ref. [7]. The concrete lining of the pressure shaft has to fulfill the design requirements of hydraulic load cases in terms of:

(1) Internal water pressure, e.g. the first filling of the shaft and during operation;

Internal head $=$ full supply level at Dyraaba Reservoir $=976 \mathrm{~m}$ a.s.l.
(2) External water pressure, e.g. when emptying the shaft for maintenance;

External head considering saturation of the rock mass due to leakage) $=$ full supply level at Dyraaba Reservoir $=976 \mathrm{~m}$ a.s.1.

Comment: Here in this paper only the design scenario of internal water pressure and the direct application of the in-situ stress measurements are addressed. The design scenario was also assessed comparing the actual rock cover with a minimum rock cover as calculated with the Norwegian criterion, and a general stress comparison using the minimum stress criterion and the stress comparison criterion.

As the concrete liner is not completely water tight, the water pressure is considered to act directly on the jointed rock surface where it tries to penetrate the rock mass by opening existing fractures. Such events may lead to significant water losses and if close to the surface or to other underground openings, cause severe damages, e.g. land-slides or the flooding of nearby caverns. The phenomenon is directly comparable to the HTPF configuration where the reopening pressure $P_{\mathrm{r}}$ represents the value of water pressure needed to open an existing fracture.

From the 31 tests performed in the boreholes ST-1 and PH-1 in the vicinity of the pressure shaft 28 results could be used for interpretation along the entire depth of the structure. Fig. 5 shows the fracture reopening pressure $P_{\mathrm{r}}$ against the depth and the design water 
pressure $P_{\mathrm{i}}$. The advantage of the comparison of $P_{\mathrm{i}}$ to $P_{\mathrm{r}}$ is that $P_{\mathrm{r}}$ is derived directly from measured data and additionally $P_{\mathrm{r}}$ simulates closely the phenomenon of a hydraulic overstress of the rock mass where fracture reopening pressure indicates the limit state where the internal water pressure exceeds the external rock mass pressure without taking into account the tensile strength of the rock mass. Therefore here no further interpretation is needed. Fig. 5 shows clearly all values being above the design water pressure $P_{\mathrm{i}}$.

\section{Conclusions}

For designing the underground structures of the UMDP (Uma Oya Multipurpose Development Project) as series of hydraulic tests using the HF (hydraulic fracturing) and the HTPF (hydraulic testing of pre-existing fractures) configuration have been performed. The results of the measurements had a direct impact on the design of the major openings bearing a high overburden - the underground powerhouse and the transformer cavern - and revealed a significant optimization potential concerning the selection of the lining system of the pressure shaft.

Still the challenging structure demands high quality materials, qualified contractors and a close site supervision including a severe control of the construction process.

\section{References}

[1] Dietler, T. 2011. Uma Oya Multipurpose Development Project; Ministry of Irrigation and Water Resources
Management of Sri Lanka: Dyraaba Power Tunnel \& Tailrace Area; Geological-Geotechnical Section 1:10,000; JV Mahab Ghodss/Pöyry DWG-No.: UMO-JV-II-130-10-DG-HD-004-00, Date: 2011.10.06。

[2] Haimson, B., and Cornet, F. 2003. "ISRM Suggested Methods for Rock Stress Estimation-Part 3: Hydraulic Fracturing (HF) and/or Hydraulic Testing of Pre-existing Fractures (HTPF)." Int. J. Rock Mech. Min. Sci. 40: 1011-20.

[3] Hubbert, M., and Willis, D. 1957. Mechanics of Hydraulic Fracturing. Trans. AIME, 210.

[4] Kirsch, G. 1898. Die Theorie der Elastizität und die Bedürfnisse der Festigkeitslehre. Zeitschrift des Vereins Deutscher Ingenieure 29. S. 797-807.

[5] Pine, R. et al. 1983. "Hydrofracturing Tests at Rosemanowes Quarry to Depths of 2000 m." Int J Rock Mech Min Sci Geomech Abstr 20: 63-72.

[6] Schmitt, D., and Zorback, M. 1989. "Poro Elastic Effects in the Determination of the Maximum Horizontal Principal Stress in Hydraulic Fracturing Tests-A Proposed Breakdown Equation Employing a Modified Effective Stress Relation for Tensile Failure." Int. J. Rock. Mech. Min. Sci. 26.

[7] Huwyler, P. et al. 2014. Uma Oya Multipurpose Development Project; Ministry of Irrigation and Water Resources Management of Sri Lanka: Concrete Lined Pressure Shaft. Detail Design and Structural Report. Concrete Liner. JV Mahab Ghodss/Pöyry DOC-No.: UMO-JV-II-635-10-DR-HD-001-1, Date: 2014.01.12

[8] Pahlavan, B. 2011. "Rock Stress Measurements Using Hydraulic Fracturing (HF) and Hydraulic Testing of Preexisting Fractures (HTPF) for Boreholes DT5a and ST1." Gamaneh Kav, Report No. 1, 30.08.2011.

[9] Pahlavan, B. 2011. "Rock Stress Measurements Using Hydraulic Fracturing (HF) and Hydraulic Testing of Preexisting Fractures (HTPF) for Borehole PH1." Gamaneh Kav, Report No. 2, 5.10.2011. 